\title{
Nerval's Diary
}

Due to a technical mistake, the paper 'Pula (Pola) and Porec (Parenzo), Croatia, August 13, 2000' was published in Vol. 201, No. 4, 2001, p. 384 and again in Vol. 202, No. 4, 2001, p. 378. For page 378 the paper 'From the Home Front or Ophthalmology versus Dermatology' was foreseen. The latter will be published in Vol. 203, No. 2, 2001.

\section{Book Review}

\section{Nanna Schürer, Joachim Kresken}

\section{Die trockene Haut}

Wissenschaftliche Verlagsgesellschaft mbH, Stuttgart 2000 $103 \mathrm{pp}$

ISBN 3-8047-1776-4

This is a small book of 100 pages that can easily be read in one afternoon if the reader is familiar with the German language. The book is divided into two main parts, each written by a different author. A basic reference list and index are also provided.

The first chapter of the book is outstanding: on 30 pages, the author has achieved the remarkable task of giving a well-balanced and up-to-date overview of stratum corneum and epidermal barrier basics that every health care professional concerned with skin care should be familiar with. This knowledge has not yet made its way into most dermatology textbooks, and it has been high time for a digestible text as a quick reference for doctors and nurses alike. The second chapter reviews clinical conditions associated with dry skin, followed by a color photo collection of average quality. Regrettably, seborrheic eczema has not been addressed (in contrast to ichthyosis hystrix), but this might be due to the author's choice of what is a 'dry' skin condition.
The second part of the book gives an overview of the therapeutic and cosmetic treatments available for dry skin conditions. The kind of product details provided in this section refers to the German market; Austrian or Swiss readers will find this section less appealing given the variable product names in each country. The author has chosen to separate a 'medical' treatment chapter from one about 'cosmetic' treatments, which results in a certain degree of redundancy, given the somewhat arbitrary definitions in this field. Together with the first part of the book, a concise chapter about the principles of corneotherapy that apply to any kind of topical skin treatment, cosmetic or therapeutic, would have made the book a more homogeneous piece of work.

Many skin care professionals who have found their way into a dermatology library to find out more about what they are actually doing when they are prescribing emollients, return frustrated, either because of the absence of relevant information or because of highly specialized texts written only for the small community of corneoscientists. That is why this booklet, as a quick reference and tutorial text, should be part of a general dermatology library.

If you are not familiar with German, or if you want to dive more deeply into the subject of dry skin, Lodén and Maibach's Dry Skin and Moisturizers (Boca Raton, CRC Press, 2000) is certainly the new reference in the field.

Dr. Jann Lübbe, Geneva

\section{KARGER}

Fax + 41613061234 E-Mail karger@karger.ch www. karger.com
(C) 2001 S. Karger AG, Base

Accessible online at www.karger.com/journals/drm 